The Geneva Papers on Risk and Insurance, 23 (No. 89, October 1998), 479-489

\title{
Challenges in Insurance Markets
}

\author{
by Antoine Bernheim*
}

I congratulate Geneva Association on reaching the 25 year milestone, a quarter of a century of brilliant successes in the service of insurance and economic science.

As chairman of Assicurazioni Generali, I am doubly delighted with this achievement because 25 years ago we were amongst the promoters for the setting up of the Association, well aware of the need to support research into the role of insurance in a modern economy.

Geneva Association has always been a fundamental reference point for the European insurance sector and has gradually increased its importance for policy makers in the face of the crisis of the welfare state and the necessity to redefine the borders between state and private interventions in all fields of social security.

Moreover, an excellent contribution to economic thought has been made as regards the concepts of vulnerability and insurability of risks: as a matter of fact, at a time when exploiting advanced technology is the key factor in modern production processes, "insurance has become a fundamental pre-condition for investment"1.

This article deals with the implication of the changes in the insurance markets on the strategy of insurers. I will express my point of view on the solutions that insurance companies have to reach in order to successfully meet the future challenges in our more and more competitive arena.

*President, Assicurazioni Generali, Italy.

${ }^{1}$ The Management of Risks and Vulnerability in the World Today, Cesar Foundation, July, 1991. 


\section{The world insurance market}

Premium volume of world insurance business was estimated at 1,730 billion ECU in $1996,1,000$ billion in life ( $58 \%$ of the total premiums) and the remaining 730 billion in non-life.

The USA, the largest insurance market in the world, collected 528 billion ECU of premiums (226 of which in life) in 1996. Premium income reached 494 billion ECU (269 billion in life) in the European Union and 420 billion ECU ( 331 billion in life) in Japan.

Premium to GDP ratio, the index which measures the weight of insurance in an economy, has been substantially stable as regards the non-life business in industrialised countries, a sign of the maturity of this market, which increases only if the economy, as a whole, improves. On the contrary, life business shows great prospects for development, in particular, in the European Union where the premium to GDP ratio rose from 3\% in 1990 to $3.9 \%$ in 1996 .

As far as the other economic areas are concerned, premium to GDP ratio is much lower in emerging countries, heralding the enormous growth prospects there and explains the great interest of leading world insurance groups to do business in these areas.

In South East Asia (income premium of 83 billion ECU), despite the slowing down in 1997 due to the well-known financial and political turmoil, the prospects remain in any case favourable in the long run. Moreover, we must not forget the Chinese market, populated by over a billion people, which may offer formidable business opportunities over the next few years.

Latin America has benefited from free trade agreements (NAFTA and MERCOSUR) and from a considerably improved political situation; as a result, GDP has grown by about $3 \%$ in real terms and inflation seems under control. In Eastern Europe, the increase in insurance business reflects the economic and financial uncertainty still characterizing this area. The insurance market is still underdeveloped because of the heritage of the Communism era, but growth rates were very high in real terms.

Let us now try to explore in more depth the factors which influence these trends in the world insurance demand and later go on to highlight the consequences these have on the strategies of insurance companies.

\section{Crisis of welfare states}

As everybody knows, a major threat to the financial stability in industrialised countries is represented by the burden of their social security systems. This is true, in particular, in the European Union, whose member states have to meet the Maastricht criteria. Here, as the Nobel Prize winner Merton Miller said, the size and growth of their public debt resemble a kind of "Ponzi scheme", a pyramid of costs that is bound to grow bigger and bigger until it crashes down.

Designed in times of fast-growing population and strong economic expansion, they do not fit today's world anymore, causing huge imbalances that have to be financed by public money. Taxes, in fact, are now so high they cannot be increased without provoking 
the taxpayer's protests and thus threatening political stability; so the only way out seems to lay with the reduction of welfare benefits.

In order to understand the reasons why social security systems are not sustainable any more and to locate the areas where private insurance may play its important social role, it is useful to split welfare spending into its main components: pensions and health care.

Demographic trends and aging of population are the well-known main causes of the financial imbalance of social security systems in western countries. The weight of pension spending is currently at its highest in European countries, where it averages more than $10 \%$ of GDP (15\% in Italy, $12 \%$ in France and $11 \%$ in Germany) against, for example, $4 \%$ in Japan and $6,5 \%$ in the States, and it is bound to soar over coming years as the share of working-age people drops ${ }^{2}$.

According to IMF figures, in fact, the dependence ratios of the elderly population (over 65 to 15-64) will double in the next 30 years in most OECD countries, exceeding 40 percent. In Europe, by 2025 over 65 s will be more than 100 million, about $30 \%$ of the entire population. In the USA, 78 million "baby-boomers" will reach retirement age as from the year $2012^{3}$.

These trends are threatening the equilibrium of pay-as-you-go systems. To limit the increase in financing public deficits, which is jeopardising the competitiveness of western industries in international markets (in the USA, this fact has become a burning issue which involves large sectors of economic and social life), policy makers have to redefine the frontier between state and private pensions.

In this respect, the establishment of private pension funds is seen by many as the road towards solving these problems and increasing personal responsibility: as Merton Miller puts it, "Isn't it better for a worker to dispose of his money, having the chance to choose how to invest it, instead of leaving to the State the task of doing it for him?"

The answer, which seems to be obvious in the USA, is far more controversial in the EU, where, currently, public pensions represent about $88 \%$ of the income received after retirement ${ }^{4}$. Any reform of the pay-as-you-go systems will, therefore, be destined to have an enormous impact on the private sector.

In Europe, the development of pension funds will be enormous in the next few years. In 1993, assets managed by pension funds in the EU amounted to 1,198 billion ECU, which represented only $20.3 \%$ of the GDP, against $59.1 \%$ in the USA and $44.7 \%$ in Japan. According to Datamonitor, assets managed by both pension funds and life insurers will increase to almost 3,000 billion ECU by the year 2000 , setting off a positive cycle for capital markets and economic development.

\footnotetext{
${ }^{2}$ World Bank.

${ }^{3}$ Best's Review: The New Financial Order Takes Shape, January 1998.

${ }^{4}$ European Commission: Green Paper on Private Pension Systems in the Single Market (Com (97) 383 def.).
} 
Again, health care expenditure is rapidly increasing in industrialised countries as a result of aging population and advances in medical science which make treatment more costly. In the USA, for instance, health care spending absorbs already more than $14 \%$ of the wealth of the nation.

To reduce this burden, countries are reorganising their health care systems by decreasing benefits and introducing stricter requisites for access to welfare state assistance. Governments are shifting part of it onto the citizen and thus making him responsible for his future while passing the task of providing these services in a cost-effective way on to a competitive market. This is creating enormous room for manoeuvre for private health insurance, which will complement, and in some cases, substitute public health care systems.

The development of health insurance is nevertheless hindered by the very high costs of medical care, which reflect on premiums and make them less competitive: this is why many insurance companies are implementing managed-care techniques for better control of cost and quality of services and are also exploring the road towards vertical integration with providers.

\section{The creation of a single market in Europe}

The European market is the most likely to be affected by structural changes in the next few years. Freedom of services is allowing insurance undertakings to provide crossborder insurance services all over Europe on the basis of the Home Country Control principle.

However, the road towards the complete integration of national markets is still long in Europe because of the presence of different cultures, languages and traditions which are undoubtedly an obstacle for personal lines where insurance demand is predominantly local. Anyway, a great impulse towards cross-border selling will come from EURO, which will enable customers to compare prices of insurance products sold in different countries and will make the insurance arena more competitive.

This is probably one of the reasons why, even though the demand still remains local, leading European groups are actively operating as if in a single market and shifting competition beyond their home countries.

\section{New trends in insurance demand}

As far as insurance demand is concerned, in industrialised countries there is a general tendency towards an increase in the insurance culture, which is changing the customers' behaviour when buying insurance. In a paper on the economic aspects of insurance distribution, OCSE wrote: "Customers' behaviour and expectations have been changing rapidly ....they can now much more easily recognise the difference in cost, quality and convenience among alternative products and services...The growing sensitivity of customer to cost, quality and convenience applies not only to insurance products themselves provided by different insurers but also services provided by different distribution channels". 5

\footnotetext{
${ }^{5}$ European Commission: Economic Aspects of Insurance Distribution, 1996.
} 
What may be observed is a shift from a supply-driven market to a demand-driven market in which the elasticity of insurance demand to price is increasing. More and more customers are demanding global covers for their security needs, choosing providers who offer the best conditions in terms of price and quality of service and paying a price for consultancy offered by intermediaries only if it is actually useful and professional.

\section{Life insurance}

As I mentioned above, in life insurance the reforms of welfare states are leading to an increase in the responsibility that individuals will have to assume for their retirement needs and those of their families. Individuals ask for more and more covers to safeguard all aspects of human life and the capacity to produce income during the entire working age.

There is, therefore, a huge potential demand for comprehensive personal risk cover including Permanent Health Insurance, Critical Illness and Long Term Care and certain niche products such as the Key Man Insurance. However, these forms of insurance, especially Critical Illness and Long Term Care, have still to be tested and adapted on many markets.

Welfare state reforms are drawing newcomers into the insurance arena, contributing to greater competition in the market and blurring the frontiers between the different sectors of managing saving. In this field, insurers have to overcome fierce competition from other financial operators (banks, pension funds, mutual funds and so on) which have consolidated know-how and low management costs.

Moreover, the increasing sophistication of consumers' needs is leading towards the substitution of traditional life covers with new products, which are becoming financial instruments by mean of which households invest their savings. This leads to an expansion of the range of life policies offered by insurance companies with products in which the financial risk is borne by the customer. Unit-linked policies may represent a new frontier for life insurers because of their superior flexibility which allows more aggressive investment strategies in order to maximise returns.

To meet these new challenges, insurers must improve their competitiveness through better management of their costs and increase their financial expertise in order to cover the needs of the client. Insurance companies are trying to promote themselves as longterm investors, capable of guaranteeing the optimal trade-off between risk and return through an adequate diversification of investment portfolios.

Asset/liability management and asset allocation will be of utmost importance in the investment policy of insurance undertakings in the next few years. Advanced risk management techniques in addition to a deep knowledge of financial and capital markets on a worldwide basis will be the factors which lead insurers to be competitive with banks and other financial institutions in managing households funds.

\section{Industrial and commercial lines}

As far as commercial lines in non-life business are concerned, corporate clients are modifying their approach to covering their risks: the increasing competition in the 
international markets, also due to the globalization of economies and the creation of a single market in Europe, has increased the sensitivity of customers to the cost of insurance services.

They show a clear tendency towards a global management of risks, self-insuring and self-retaining those characterised by high frequency and low claims severity. Clients are asking for quasi-insurance services such as loss prevention or claims settlement and are setting up captives in order to maintain cash flow while limiting insurance to property catastrophic exposures, business interruption or environmental and product liability risks.

There is, therefore, a process of insurance disintermediation, which causes a decline in the insurance demand in commercial lines in most industrialised countries. What makes this tendency worse is the shift from manufacturing to service industries, leading to lower insurance demand compared to output, which is restraining the insurance development in most developed countries. In Europe, for instance, Mc Kinsey estimated that there might be a reduction in the volume of premiums by up to $50 \%{ }^{6}$ by 2005 . I hope that this catastrophic forecast will not take place, but, in any case, it clearly highlights the depth of the changes in our market.

Insurance disintermediation is, however, at least partially compensated by the demand for covering new risks which are emerging under the pressure of social expectations concerning environment and consumer protection. Furthermore, stricter legislation is leading to a wider concept of "enterprise liability", attributing enterprises with the social costs of external diseconomies caused by production processes. Industrial companies need, therefore, more complete and sophisticated covers and insurers face numerous problems in quoting new risks because of the lack of statistical experience.

Moreover, exposure is rapidly growing: property risks are now much higher than in the past due to changes in production processes through a greater concentration of plants and a more intense use of technology in production cycles. The growing interdependence of production processes is forcing customers to ask for more comprehensive covers, in terms, for instance, of business interruption guarantees.

Exposure to catastrophic loss due to natural forces is also rising because of the expansion of insurance business in the geographical areas that are more exposed to natural disasters. This is due to the globalization of industrial production and more investment in areas, such as Eastern Europe and the Far East.

The increasing severity of claims and the need for sophisticated risk management require more underwriting capacity and adequate risk-knowledge. This tendency is favouring reinsurers, who have over-capacity due to the lack of catastrophic damages in recent years and a consolidated know-how in insuring commercial and industrial risks. Some of them are becoming a sort of direct providers of insurance services, contact their clients directly, manage their risks, and, later, look for fronting companies to issue policies. This causes a downward pressure on rates, profitability is reduced and few of these providers will be able to survive in the future insurance market.

${ }^{6}$ Mc Kinsey Quaterly: New Strategies for European Insurance, 4, 1996. 


\section{Distribution: New distribution channels in personal lines}

The development of innovative distribution channels is changing the way of selling policies in personal lines. More and more customers tend, in fact, to turn to new low cost channels, such as banks and direct writers, because they no longer consider the costs of traditional intermediaries (brokers and agents) justifiable for the added-value created in providing the services.

It is worth mentioning the success of new channels in some countries. In France, banks are collecting more than $50 \%$ of the entire life premium income; in Italy, banks are going to become the first distribution channel in 1998. In the UK, roughly one third of motor insurance premiums are transacted by fifteen or so companies via telephone. In Europe, more than 100 direct writers are trying to imitate the success achieved by Direct Line, which, in few years, has become the leader in the British motor insurance market.

As is well-known, banks have competitive advantages over the traditional channels: apart from lower charges, they have frequent contact with their clients and superior knowledge of the client's financial means. On the contrary, they are not able to sell complex products due to the lack of insurance expertise of banking staff.

The success of telephone marketing depends on an intelligent synthesis between a new approach to the client and an efficient and ample use of technology. This channel allows insurers to contain distribution costs and be more competitive in selling standardised products, apart from establishing direct contact with customers and creating a strong brand image.

Moreover, Internet may be the new frontier in drawing up contracts. With the explosion of telecommunication technology customers may navigate in the virtual world, compare prices and conditions of contracts proposed via Internet and sign them directly from their houses, sitting comfortably in front of a computer. According to a Datamonitor study", the "use of the Internet will grow tremendously because the Internet is the most cost effective way of distributing insurance ever invented". Datamonitor estimated that in the USA this new distribution channel will collect $\$ 2.4$ billion premiums by the year 2000 .

\subsection{Changes in traditional sales network}

Traditional sales forces will have to profoundly restructure their way of distributing insurance policies in order to avoid going out of the market. In the UK, in fact, the arrival of telephone selling has determined the closure of a large number of broker agencies.

The strategy of some traditional intermediaries is that of segmenting the market and focusing on middle risks which are difficult to standardise. Traditional channels will have to create added-value for customers in the face-to-face process in the long run. To do this, they will have to understand the needs of their clients, propose appropriate tailor-made policies and remain in the service of their clientele during the entire life of the policies.

In commercial lines, even brokerage houses may not be pure intermediaries between clients and insurers anymore, but will have to offer their customers a global and highly

${ }^{7}$ Insurance on Internet, 1996-2000, 1996. 
qualified consultancy in loss prevention and managing risks. The need for corporate clients to contain insurance costs is leading to a reduction in brokers' revenues, which tend now to be fee-based, and is probably the main reason for the concentration process that is currently in progress amongst brokerage houses.

\section{Technology}

A considerable portion of current changes in insurance markets are due to information technology, which is creating new opportunities for doing business favouring the development of new distribution channels, reducing costs and increasing efficiency. Until a few years ago, production and consumption of an insurance service happened in the place where risks were located. To run a business, a company had to have a local sales and claims settlement network. Today, thanks to the progress in telecommunications, one may accept insurance proposals from a workstation, even if the risk is located in other countries and takes part in insurance and reinsurance international programmes.

We are on the threshold of an explosion of the communication network and, therefore, a change, after the mainframe era, from the personal computers of today to computer stations, characterised by networks of computing systems allowing each individual to access data and programs of any other user on the same network. More powerful computers allow staff to communicate with suppliers and clients, each in their own workplace on a worldwide basis.

Even Lloyds of London has modified its secular way of running business, passing from slips to computer transactions. In Europe, insurers underwrite insurance contracts in a less impersonal way through dedicated networks, such as Limnet, Rinet, Assimet, Rita and Win, which are available only for a limited number of undertakings, those more qualified and able to support the relevant investment costs necessary to access these structures.

Moreover, there will be no limit to the development of the chip or the disk in the next decade and, therefore, to the power of computing and memorising data. Large amounts of data may be more easily memorised on computers to support more sophisticated analyses on risks and clients, the crucial elements in underwriting and segmenting markets for risk selection and marketing strategies.

\section{Insurance companies strategies}

Having completed the examination of the main factors which are influencing insurance markets today, I am now going to describe how these trends are reflecting on insurers' strategies.

What is often being said with regard to the changes that are affecting the insurance market today is that the "golden age" is over for insurers. To survive, insurers will have to meet these challenges and rapidly adapt to the new rules of the game. The winning strategies may be summarised under four headings representing factors that may be worthwhile to explore: 
- know-how

- technology

- cost containment

- capital

\subsection{Know-how}

The increasing sophistication of the insurance demand is leading to greater innovation in the range of products offered in the market. Insurers have to improve their global "know-how" in analysing the insurance market, introducing advanced methodologies in classifying clients in homogeneous segments and identifying potential demand, designing customised products, quoting old and new risks and improving face-toface selling techniques in order to establish stable relationships with customers.

With the blurring of the frontiers between financial products in managing household savings, insurers will have to develop products with different risk profiles and potentiate their know-how in asset allocation, in asset/liability management and in managing financial resources in order to offer the best trade-off between risk and return.

What clearly emerges, in this scenario, is the crucial importance of research and development.

R\&D is a process which has to be aimed at foreseeing future changes, innovating the way of doing business and the technical background of the company. R\&D is, however, the tip of an iceberg, which involves the entire company and, therefore, its organisation and processes, but, in particular, it involves human resources, who have to be oriented towards innovation and change in order to fully exploit the advancement in insurance science.

\subsection{Technology}

As far as technology is concerned, I can say that it is the necessary condition in order to be competitive in today's insurance market, but it is not sufficient in itself. In fact, all large organisations have the same opportunities to invest in technology, application packages (ERT) are standardised all over the world, the global information technology market is dominated by few vendors of software and hardware, communication networks are accessible to everyone from anywhere and Internet is breaking down frontiers and creating a single " world-country".

The competitive advantage for insurance companies is, therefore, different and it is one of integrating technology in their organisation and processes. It requires an increase in the culture of the entire staff and management of a company and a complete redesigning of the company-model, which has become technology-oriented.

\subsection{Cost containment}

Exploitation of technology on a vast scale is also a basic instrument in cost containment. Technology leads to a less labour-intensive process and a cost effective organisation. Now, the revolution in communication networks allows leading groups to 
concentrate common activities and obtain economies of scale, setting aside the localisation of subsidiaries.

But, as for technology, cost containment is not only being pursued through reduction of staff in order to increase productivity, but also when redesigning the entire companymodel and its organisation, re-engineering and restructuring enterprises processes and outsourcing some basic functions, such as data elaboration or claims settlement.

The search for economies of scale is one of the reasons for the wave of merger \& acquisition in progress in the insurance markets, which involves not only insurers, but also brokerage houses and reinsurers. Apart from pursuing the rationalisation of operational structures, companies focus their strategies on developing new markets, even through new distribution channels, in order to compensate for the decline in the unitary profit margins with larger business volume.

Moreover, international business diversification is a way of reducing the danger constituted by the fluctuations of insurance cycles and political turmoil, but it is also a way of capitalising experience from the presence in other markets.

One consequence of this strategy is the change in the size and complexity of insurance groups.

Merger mania is an effective neologism coined to describe the incredible number of operations which have marked the 90s. Mergers between Sun Alliance and Royal Insurance, General Accident and Commercial Union in the British market, AXA and UAP in France, the takeover of AGF by Allianz and AMB by Generali, the agreement between BAT and Zurich have all created giants in the European market. At stake is the objective of being a leading company in Europe, which is now considered a domestic market, and being more competitive by cutting costs and expanding business in emerging markets.

In 1990, for instance, the top ten insurance groups in Europe collected premiums for 95 billion ECU corresponding to $32 \%$ of the entire insurance business done in Europe. Hypothesizing that the abovementioned operations were concluded in 1996, premium income of the ten leading groups rose to 250 billion ECU, over $50 \%$ of the European Union global business.

Merger mania, however, is not only affecting insurers. There is also a global battle which is involving leading brokers: AON took over Alexander \& Alexander, Marsh \& McLennan acquired Johnson \& Higgins, Sedwick is expanding in southern Europe and Latin America and Willis Corroon in France and Germany. Other relevant acquisitions involved reinsurers, for instance, Munich $\mathrm{Re}$ bought American $\mathrm{Re}$ and Swiss $\mathrm{Re}$ Mercantile \& General.

What may be observed is, therefore, a battle amongst giants. The market will become more and more concentrated and some lines of insurance will be dominated by few big players. Bests estimated that the number of insurers running property $\&$ casualty business will decrease to 50 from the current two thousand in the next few years. 


\subsection{Capital}

All these operations require sizeable capitalisation.

Today, insurers have to invest more financial resources in order to develop new business in international markets or in different lines of insurance, restructure their internal processes and organisation, implement new distribution channels, finance research\&development projects and acquire advanced information technology.

New share capital is also necessary to increase solvency which is threatened by fierce competition and the increase in claims severity and catastrophic losses, apart from the need to comply with new stricter solvency requirements aimed at reinforcing the stability of the insurance industry and eliminating "double gearing". In this context, stricter solvency rules are being introduced in the European Union; in the USA, RBCs were implemented at the beginning of the 90 s.

The demand for share capital depends obviously on the capacity of the management to increase the value of the company in the medium and long run. ROE, risks and growth are the critical factors used by financial investors and rating agencies in the calculation of the value of insurance undertakings and these elements are the result of the quality and the vision of management on the future strategies on the market.

\section{Conclusion}

I am going to conclude this article by summarising what I have discussed with one concept: insurers have entered a new era and only players who adapt their strategies to the new rules of the game will survive.

It means that insurers have to look at business from a new viewpoint and be open to changes. In this scenario, innovation is a key element to success.

Innovation in the technical area to design new products and improve investment policy; innovation in distribution based on the improvement of quality of services for customers; innovation in organisations and processes, innovation in information technology, innovation in human resources culture.

Innovation also means research and development, which companies have to promote in order to adapt to the new way of doing business. Never before has there been such a fertile ground for research in the insurance field. This is a challenge, however, which does not involve only insurers, but also research centres. Here, my mind is running to Geneva Association, acting as a pioneer in this kind of study, and I am certain that it will continue to do so in the service of insurance science, as it has done for 25 years. 